\title{
MODULATIONS OF THE VISUAL N1 COMPONENT OF EVENT-RELATED POTENTIALS BY CENTRAL AND PERIPHERAL CUEING
}

Sonia Doallo, Laura Lorenzo-López, Carmen Vizoso, Socorro Rodríguez Holguín, Elena Amenedo, Salvador Bará, Fernando Cadaveira

This is the peer reviewed version of the following article: Doallo S; Lorenzo-López L; Vizoso C; Rodríguez Holguín S; Amenedo E; Bará S; Cadaveira F (2005). Modulations of the visual N1 component of event-related potentials by central and peripheral cueing. Clinical Neurophysiology, 116, 807-820, which has been published in final form at https://doi.org/ 10.1016/j.clinph.2004.11.013. This article may be used for non-commercial purposes in accordance with Elsevier Terms and Conditions for Use of Self-Archived Versions 


\section{Modulations of the visual N1 component of event-related potentials by central and peripheral cueing}

\footnotetext{
S. Doallo ${ }^{\mathrm{a}}$, L. Lorenzo-López ${ }^{\mathrm{a}}$, C. Vizoso ${ }^{\mathrm{a}}, \mathrm{S}$. Rodríguez Holguín ${ }^{\mathrm{a}}$, E. Amenedo ${ }^{\mathrm{a}}$, S. Bará ${ }^{b}$, F. Cadaveira ${ }^{a}$

a Departamento de Psicoloxía Clínnica e Psicobioloxía, Facultade de Psicoloxía, Universidade de Santiago de Compostela, Campus Universitario Sur, E-15782, Santiago de Compostela, Galicia, Spain

${ }^{\mathrm{b}}$ Departamento de Física Aplicada, Facultade de Física, Universidade de Santiago de Compostela, Galicia, Spain

Corresponding author: Sonia Doallo, Departamento de Psicoloxía Clínica e Psicobioloxía, Facultade de Psicoloxía, Universidade de Santiago de Compostela, Campus Universitario Sur, E-15782, Santiago de Compostela, Galicia, Spain. Telephone: +34.981.563.100 (Ext. 13916), Fax No: +34.981.528.071, Email address: sdoallo@usc.es.
} 


\begin{abstract}
Objective: The aim of this study is to investigate the effects of the central and peripheral cueing on N1 component of the event-related potentials (ERPs) and the time course of these effects. Methods: ERPs were recorded while participants performed a discrimination task on the height of target bars, which were presented after informative-central, informative-peripheral or uninformative-peripheral cues with stimulus onset asynchronies (SOAs) of 100, 300, 500 or 700 ms. Results: Peripheral cues (informative and uninformative) elicited stronger effects of cue validity on N1 $300 \mathrm{~ms}$ after cue onset, whereas central cues led to a more sustained validity effect on $\mathrm{N} 1$, with later stronger effects, at $500 \mathrm{~ms}$ SOA. Conclusions: The present data showed that central and peripheral cues affected to the level of processing reflected by the $\mathrm{N} 1$ component, but there were differences in the time course of these effects. Attentional orienting in response to central cueing resulted in a sustained validity effect on N1, relative to the more transitory activation of the process reflected by the $\mathrm{N} 1$ validity effect in this peripheral cueing task. Significance: This study provides a detailed within-subject analysis of the time course of the effects of central and peripheral cueing on N1.
\end{abstract}

\title{
Keywords
}

Visuospatial attention; Central cues; Peripheral cues; N1; Event-related potentials 


\section{Introduction}

Orienting of visuospatial attention has been extensively studied by spatial cueing paradigms, in which a cue informs subjects about the probable location of a forthcoming target stimulus. Stimuli presented at the cued location (valid trials) are detected and discriminated faster and more accurate than are stimuli appearing at uncued locations (invalid trials). These attentional effects occur in absence of eye movements (covert orienting of attention), as has been demonstrated by studies using both central and peripheral cueing (Jonides, 1981; Müller and Rabbitt, 1989; Posner, 1980; Posner et al., 1978), and have been interpreted as a consequence of enhanced sensory processing of stimuli at attended locations (Posner, 1980). Behavioral studies suggest that two different attentional mechanisms underlie attention shifts by these two types of cue: one voluntary (or endogenous) associated with central cueing and one involuntary (or exogenous) triggered by peripheral cues (Briand and Klein, 1987; Jonides, 1981; Müller and Rabbitt, 1989). When a peripheral cue is informative of the target position it triggers both exogenous and endogenous mechanisms of attention.

Several event-related potentials (ERP) studies have shown that this improved performance by valid cueing is accompanied by amplitude enhancements of P1 or N1 components or both (Anllo-Vento, 1995; Eimer, 1994a; Fu et al., 2001; Hillyard et al., 1994; Hopfinger and Mangun, 1998; Mangun and Hillyard, 1991; Mangun et al., 1987). The amplitude modulations of the P1 and N1 components by visuospatial attention have been interpreted as a sensory gain control mechanism that results in enhanced perceptual processing of stimuli presented at attended locations (Mangun and Hillyard, 1990; Mangun et al., 1987). However, several studies have reported dissociations between the P1 and N1 attention effects in different visuospatial attention tasks (Heinze and Mangun, 1995; Heinze et al., 1990; Luck and Hillyard, 1995; Luck et al., 1990; Mangun and Hillyard, 1991). These dissociations suggest that these two ERPs components reflect different attentional processes (for review, see Luck, 1995). There is evidence showing that the P1 amplitude modulations reflect an attentional gain control within extrastriate visual cortex (Gómez et al., 1994; Heinze et al., 1994; Mangun et al., 1993, 1997; Martínez et al., 1999). Luck et al. (1994), in a spatial cueing study including neutral trials — which allow to distinguish between attentional benefits and costs - found reduced P1 amplitudes to invalid trials compared to neutral trials, suggesting that P1 attention effect may reflect a mechanism that suppresses information from unattended locations.

The functional significance of the N1 attention effect has been not well established yet. Luck (1995), on the basis of several lines of evidence, proposed that it reflects a limited capacity discriminative 
process that is applied to attended stimuli'. ${ }^{1}$ First, the N1 attention effect reflects an enhanced processing of stimuli at the attended location (Luck and Hillyard, 1995; Luck et al., 1994). Second, it is present only when subjects perform a discrimination task at the attended location (Mangun and Hillyard, 1991). Third, the N1 attention effect appears to be reduced or suppressed when the time between successive stimuli at the attended location is short (Heinze et al., 1990; Luck et al., 1990), which may indicate that it reflects a limited-capacity process. Additional evidence for the hypothesis that the $\mathrm{N} 1$ component reflects a visual discriminative process at attended locations was provided by Vogel and Luck (2000). Similarly, in a recent study combining ERP and magnetoencephalographic (MEG) recordings, Hopf et al. (2002) found a larger negativity in the N1 latency window when subjects performed a discriminative response as compared with a simple response over regions of inferior occipital or occipito-temporal cortex. These authors suggested that this N1 discrimination effect reflects a top-down modulation of discriminative processing in areas of the ventral visual stream.

It has not been either well characterized what are the N1 modulations by central and peripheral cueing, which would allow to obtain a clear picture about the effects of voluntary and involuntary allocation of attention on this component.

Several studies of central cueing have found amplitude enhancements of the N1 component for validly cued stimuli relative to invalidly cued stimuli (validity effect) at posterior sites (Hillyard et al., 1994; Mangun and Hillyard, 1991). The attentional effects of peripheral cueing on N1 component are less clear. The findings reported from ERP studies using peripheral cues seem to change when different stimulus onset asynchronies (SOAs) are employed. Those studies that have used long SOAs (Eimer, 1994a; Hillyard et al., 1994) have reported validity effects on N1 at posterior sites, consistently with central cueing studies. Nevertheless, more recently Pesce and Bösel (2001) reported about an enhanced positivity in the early $\mathrm{Nd}$ time interval $(130-180 \mathrm{~ms}$ ) to unilateral peripheral cueing (vs. bilateral peripheral cueing) using both long and short SOAs (500 and $100 \mathrm{~ms}$, respectively). On the other hand, McDonald et al. (1999) found that cue validity did not influence the N1 component using uninformative-peripheral cues with long SOAs, which suggest that the informative value of the peripheral cues may be another factor influencing on the N1 wave. To our knowledge, there are no studies that had addressed the effects of uninformative-peripheral cues on N1 component with short SOAs. Those studies that have used short SOAs with informative-peripheral cues have reported diverse

\footnotetext{
${ }^{1}$ The visual N1 component can be divided into anterior and posterior subcomponents, with different latencies. The attention effects on the anterior and posterior N1 waves can be dissociated under some experimental conditions (Heinze et al., 1990). It is the posterior N1 effect that has been proposed to reflect the application of a discrimination mechanism to stimuli at the attended location (Hillyard et al., 1999).
} 
results. With an SOA of 100-300 ms, Fu et al. (2001) observed that contralateral N1 was smaller in valid than in invalid trials, but the ipsilateral N1 was larger for valid than for invalid trials at occipitaltemporal sites. Anllo-Vento (1995) did not find a significant validity effect on P1/N1 with an SOA of $200 \mathrm{~ms}$, which was present when the SOA was $600 \mathrm{~ms}$, whereas Eimer (2000) found an enhanced negativity for valid trials using a cue-target interval of $200 \mathrm{~ms}$ (but see Pesce and Bösel, 2001).

The objectives of the present study were to examine the effects of the central and peripheral cueing on $\mathrm{N} 1$ component and to assess in detail the time course of these effects. To accomplish this, we used a paradigm adapted from Hillyard et al. (1994). In a previous paper (Doallo et al., 2004), we analyzed the effects of the spatial cueing on P1 component. The present study reports about the results involving the N1 component, which will allow to compare additionally the time course of the modulatory effects of central and peripheral cues on these two components.

\section{Materials and methods}

\section{Subjects}

Fifteen paid volunteers (12 female, 3 male), aged between 19 and 23 years ( $M=20$ years), took part in the experiment. ${ }^{2}$ Informed consent was obtained from each participant. All the subjects were righthanded, had normal or corrected-to-normal vision, and had no history of psychiatric or neurological disorders.

\section{Stimuli and apparatus}

The subjects were seated in a comfortable armchair in an electrically isolated, sound- and lightattenuated room, with response buttons under their left and right hands. A computer screen was placed $100 \mathrm{~cm}$ in front of the subject's eyes and positioned so that the stimuli (white-on-black) were presented directly horizontal to the subject's line of vision. A fixation cross was presented continuously at the center of the screen. In the Informative-Central Cue condition, each trial began with an arrow flashed at the fixation point for $34 \mathrm{~ms}$ that pointed either to the left or right visual field on a random basis (each with a probability of 0.50 ). The cue correctly indicated target location in $75 \%$ of trials (i.e. cue validity

\footnotetext{
${ }^{2}$ In the uninformative-peripheral cue condition, the data from one subject were discarded because of excessive horizontal eye movements to the cued location.
} 
$75 \%$; valid trials). The target stimuli were either short $\left(1.78^{\circ} \times 0.78^{\circ}\right)$ or long $\left(2.18^{\circ} \times 0.78^{\circ}\right)$ vertical bars flashed for $75 \mathrm{~ms}$ in the left or right visual field at a horizontal distance of 6.48 from the central cross. The target locations were each defined by four continuously present dots that formed the corners of a vertical rectangle $\left(1.58^{\circ} \times 1.18^{\circ}\right)$ centered on the target's position. The interval from cue onset to target onset (SOA) had four values of 100, 300, 500 and $700 \mathrm{ms,}$ which varied between blocks. The intertrial intervals were $1800 \mathrm{~ms}$. In the Informative-Peripheral Cue condition, stimuli and procedures were identical to those described for the Informative-Central Cue condition, except for the character of the cue: the trials began with a peripheral cue that consisted of a brief displacement of the dots that marked one of the target locations. The four dots were removed and replaced for $50 \mathrm{~ms}$ by another four dots that formed a new outline rectangle of $1.18^{\circ} \times 0.58^{\circ}$. The original dots were then restored, giving the appearance that the continuously present marker dots had jumped toward and then away from each other. The cue correctly indicated target location in $75 \%$ of trials (i.e. cue validity $75 \%$; valid trials). The cue-target SOAs were identical to those in the Informative-Central Cue condition. In the Uninformative-Peripheral Cue condition, the stimuli and procedures were identical to those in Informative-Peripheral Cue condition, except that the cue correctly indicated target location in only $50 \%$ of trials (i.e. cue validity $50 \%$; valid trials).

\section{Procedure}

For all conditions, subjects maintained eye fixation on the central cross, and were required to discriminate the height of the target bar for each trial, pressing one button with one hand for short bars and another button with the other hand for long bars, as quickly and accurately as possible in each trial. The assignment of the response hand was counterbalanced across subjects. The subjects were informed of the probabilities of the valid and invalid trial types and were told to make use of this information to maximize their performance. In order to familiarize the subjects with these specific task requirements, several training trials were run at the beginning of the experiment. Each experimental condition consisted of 4 trial blocks, according to the SOA variable, resulting in a total of 12 experimental blocks. Each block consisted of 240 trials. The order of the blocks within each experimental condition was counterbalanced for order effects within and across subjects. In the Informative-Central Cue and Informative-Peripheral Cue conditions, 180 (75\%) of the 240 trials per block were valid. In the Uninformative-Peripheral Cue condition, 120 (50\%) of the 240 trials were valid. Each condition lasted approximately $35 \mathrm{~min}$. Short breaks were allowed between conditions, with length of the break controlled by the subjects. The order of the conditions was counterbalanced across subjects. 


\section{Recording}

The electroencephalogram (EEG) was recorded with tin electrodes from T5 and T6 (according to the 10-20 system), from PL and PR (located halfway between Pz and the ear canal), and from OL and OR (located halfway between $\mathrm{O} 1$ and $\mathrm{T} 5$, and $\mathrm{O} 2$ and T6, respectively). All electrodes were referred to an electrode placed over the nose. The horizontal electrooculogram (EOG) was recorded bipolarly from electrodes at the outer canthi of both eyes, and the vertical EOG was recorded from electrodes placed supraorbitally and infraorbitally to the left eye. EEG was amplified $10 \mathrm{~K}$ and filtered using a bandpass filter of $0.05-100 \mathrm{~Hz}$. EEG and EOG were sampled with a digitization rate of $500 \mathrm{~Hz}$. Impedances were kept at $10 \mathrm{~K} \Omega$ or less. Reaction times were recorded for each trial.

\section{Data analysis}

The EEG and EOG were digitally filtered off-line with a $0.1-30 \mathrm{~Hz}$ bandpass filter, and were epoched into periods of $450 \mathrm{~ms}$, from $50 \mathrm{~ms}$ prior to the onset of the target to $400 \mathrm{~ms}$ post-target. Trials with eyeblinks, horizontal eye movements, or response errors were excluded from analysis. The EEG was averaged separately for all combinations of task conditions (visual field: right/left; trial validity: valid/invalid; type of cue: informative-central/informative-peripheral/uninformative-peripheral; cue-totarget SOAs: 100/300/500/700 ms), resulting in 48 average waveforms for each subject and electrode site. The number of trials per average ERP was similar for all conditions, with an average of $15 \%$ of rejected trials. All measurements were taken relative to the mean voltage of the pre-target interval. To avoid overlapping of ERPs elicited by cues and targets in the conditions with short SOAs, a correction was applied as follows: The ERPs elicited by cues (left and right hemifield separately) were obtained in the SOA-700 condition (epoch 0-700 ms), ${ }^{3}$ which can reasonably be assumed not to overlap with the subsequent target response. These cue ERPs were then time-locked and subtracted from the ERPs elicited by the targets in the SOA-100 and SOA-300 conditions, ${ }^{4}$ so eliminating the putative effects of

\footnotetext{
${ }^{3}$ To obtain these ERP averages, artifact rejection was performed with the same criteria employed for the averages object of this study.

${ }^{4}$ This subtractive procedure could not be applied in the SOA-500 condition because it would be necessary a longer SOA condition than one used in this study $(700 \mathrm{~ms})$ in order to subtract this cue ERP from the ERPs elicited by the targets at $500 \mathrm{~ms}$ SOA. That is, the subtraction of the ERPs elicited by cues in the SOA-700 condition from the ERPs elicited by targets in the SOA-500 condition, would lead to a correction only in the first part of the epoch that was relevant for this experiment.
} 
the electrophysiological response to the cue on the ERPs elicited by the targets. (See the appendix for a further description of the procedure to correct for possible ERP overlapping).

The averaged ERPs were analyzed with a semi-automatic peak detection program, which examined a latency window of 130-225 ms for N1 peak. Peaks were then verified and adjusted by visual inspection. Amplitude values were automatically exported to an ASCII file for subsequent analysis. To examine the N1 modulations by central and peripheral cueing, separate analyses were made for each type of cue. Repeated-measures analyses of variance (ANOVA) were performed on amplitude values with the within-subject factors electrode (6 levels), validity (2 levels), laterality (target stimuli in the contralateral vs. ipsilateral visual field relative to the electrode location: 2 levels) and cue-to-target SOA (4 levels). Significance levels were determined using degrees of freedom after applying the Greenhouse-Geisser correction when the data violated the assumption of sphericity. Post-hoc comparisons were performed using the Bonferroni adjustment for multiple comparisons. For the reaction time data, repeated-measure ANOVAs were carried out for the factors cue-to-target SOA, validity and visual field of stimulus. The reported data include only the effects of validity and its interactions with the other variables included in the analysis, since these are the most relevant to the goals of this study.

\section{Results}

\section{Behavioral performance ${ }^{5}$}

Reaction times were significantly faster for validly cued targets than for invalidly cued targets for informative-central cues $(563 \pm 55$ vs. $598 \pm 58: F(1,14)=81.188, P=0.0005)$, informative-peripheral cues $(558 \pm 66$ vs. $583 \pm 62: F(1,14)=45.364, P=0.0005)$ and uninformative-peripheral cues $(569 \pm$ 71 vs. $584 \pm 69: F(1,14)=11.725, P=0.004)$.

The factor validity significantly interacted with SOA for informative-peripheral cues $(F(3,42)=5.766$, $P=0.002)$ and uninformative-peripheral cues $(F(3,42)=14.486, P=0.0005)$, revealing that the validinvalid difference in RT varied significantly among SOAs for both conditions. For informativeperipheral cues, there was a significant validity effect at $100 \mathrm{~ms} \mathrm{SOA}(F(1,14)=43.537, P=0.0005)$, $300 \mathrm{~ms} \operatorname{SOA}(F(1,14)=24.360, P=0.0005)$ and $500 \mathrm{~ms} \mathrm{SOA}(F(1,14)=11.663, P=0.004)$. For

\footnotetext{
${ }^{5}$ Tables reporting mean RT as a function of SOA, visual field and validity for each cueing condition can be consulted in Doallo et al. (2004).
} 
uninformative-peripheral cues, the largest validity effect was observed at $100 \mathrm{~ms} \operatorname{SOA}(F(1,14)=$ 100.084, $P=0.0005$ ), while there was no significant effect at 300, 500 or $700 \mathrm{~ms}$ SOAs. There was no significant validity x SOA interaction for informative-central cues: significant validity effects on RT were observed at all SOAs.

\section{Event-related potentials}

\section{Informative-central cueing}

The mean values of N1 amplitude to valid and invalid trials at parietal, temporal and occipital sites contralateral and ipsilateral to the target location are shown in Table 1.

Table 1

The validity main effect was not significant, but this factor significantly interacted with $\operatorname{SOA}(F(3,42)$ $=3.770, P=0.017)$, revealing that the N1 amplitude tended to be smaller for valid than for invalid trials at $100 \mathrm{~ms} \mathrm{SOA}$, but larger for valid than for invalid trials at 300, 500 and $700 \mathrm{~ms}$ SOAs (see Fig. 1).

\section{Figure 1}

Significant 3-way interactions between electrode, validity and $\operatorname{SOA}(F(15,210)=2.837, P=0.028, \varepsilon$ $=0.292)$ and validity, laterality and $\operatorname{SOA}(F(3,42)=3.113, P=0.036)$ were also detected. Separate analysis for each SOA showed that the valid-invalid difference reached statistical significance at 100 $\mathrm{ms}(F(1,14)=5.799, P=0.030)$ and $500 \mathrm{~ms}(F(1,14)=6.826, P=0.020)$ SOAs. Additional analysis for each electrode at $100 \mathrm{~ms}$ SOA showed that the N1 amplitude was significantly smaller for valid than for invalid trials at left parietal $(F(1,14)=8.474, P=0.011)$, left occipital $(F(1,14)=7.691, P=0.015)$ and left temporal $(F(1,14)=7.579, P=0.016)$ sites (see Fig. 2$)$.

\section{Figure 2}

For the $500 \mathrm{~ms}$ SOA, N1 was larger for valid than for invalid trials over parietal (PL: $F(1,14)=9.385$, $P=0.008$; PR: $F(1,14)=7.401, P=0.017)$, left temporal $(F(1,14)=5.177, P=0.039)$ and left occipital $(F(1,14)=6.252, P=0.025)$ scalp locations (see Fig. 3). For the $300 \mathrm{~ms} \mathrm{SOA}$, although there was no a main effect of validity, it was found significant electrode $\mathrm{x}$ validity $(F(5,70)=5.237, P=0.004, \varepsilon=$ 
$0.579)$ and electrode $\mathrm{x}$ validity $\mathrm{x}$ laterality $(F(5,70)=6.315, P=0.020, \varepsilon=0.227)$ interactions. Separate analysis for each electrode revealed that N1 amplitude was significantly larger for validly cued targets than for invalidly cued targets over right posterior sites to ipsilaterally presented stimuli. This was shown by significant validity $\mathrm{x}$ laterality interactions at right parietal $(\mathrm{PR}: F(1,14)=9.531, P=0.008)$, right occipital $(\mathrm{OR}: F(1,14)=11.189, P=0.005)$ and right temporal $(\mathrm{T} 6: F(1,14)=11.724, P=$ 0.004) scalp locations, along with significant effects of validity at ipsilateral sites (PR: $F(1,14)=$ 12.566, $P=0.003$; OR: $F(1,14)=6.372, P=0.024$; T6: $F(1,14)=6.944, P=0.020$ ) (see Fig. 4).

Figure 3 and Figure 4

For the $700 \mathrm{~ms}$ SOA, the difference between valid and invalid trials did not reach statistical significance, and none of the variables included in the analysis showed significant interaction with validity. Fig. 5 displays the grand-averaged ERPs for valid and invalid trials at parietal, temporal and occipital electrodes ipsilateral and contralateral to the target location at $700 \mathrm{~ms}$ SOA.

Figure 5

\section{Informative-peripheral cueing}

Table 2 shows the mean values of N1 amplitude to valid and invalid trials at parietal, temporal and occipital sites contralateral and ipsilateral to the target location.

Table 2

There was no a significant main effect of validity on N1 component, but this factor significantly interacted with electrode and $\operatorname{SOA}(F(15,210)=5.050, P=0.0005, \varepsilon=0.367)$. Separate analysis for each SOA showed that a significant main effect of validity was found at $300 \mathrm{~ms} \mathrm{SOA}(F(1,14)=4.692$, $P=0.048)$. Fig. 6 shows the grand-averaged ERPs for valid and invalid trials at parietal, temporal and occipital electrodes ipsilateral and contralateral to the target location for the $300 \mathrm{~ms}$ SOA. The N1 amplitude was significantly larger for valid than for invalid trials at ipsilateral electrodes to the target location, as suggested by the validity $\mathrm{x}$ laterality interaction $(F(1,14)=6.581, P=0.022)$ and the main effect of validity at ipsilateral scalp locations $(F(1,14)=10.004, P=0.007)$. Moreover, the N1 validity effect was lateralized to the left hemisphere, as indicated by the significant electrode $\mathrm{x}$ validity interaction $(F(5,70)=5.001, P=0.018, \varepsilon=0.353)$ along with significant main effects of validity at left electrodes $(\mathrm{PL}: F(1,14)=11.029, P=0.005 ; \mathrm{OL}: F(1,14)=6.497, P=0.023$; T5: $F(1,14)=5.707$, 
$P=0.032)$. This validity effect at left electrodes was also ipsilateral, as indicated by the validity $\mathrm{x}$ laterality interactions at left scalp locations (PL: $F(1,14)=12.339, P=0.003$; OL: $F(1,14)=10.075$, $P=0.007$; T5: $F(1,14)=8.322, P=0.012)$, and by the persistence of the validity effect over these locations when stimuli were presented ipsilaterally $(\mathrm{PL}: F(1,14)=19.927, P=0.001$; OL: $F(1,14)=$ 14.664, $P=0.002$; T5: $F(1,14)=16.836, P=0.001)$.

\section{Figure 6}

There were no significant effects of validity, and no significant interactions between this factor and other factors at 100,500 or $700 \mathrm{~ms}$ SOAs.

\section{Uninformative-peripheral cueing}

The mean values of N1 amplitude to valid and invalid trials at parietal, temporal and occipital sites contralateral and ipsilateral to the target location are shown in Table 3.

\section{Table 3}

Although no main effect of validity was found, there was a significant interaction between electrode, validity and $\operatorname{SOA}(F(15,210)=4.911, P=0.002, \varepsilon=0.261)$. Separate analysis for each SOA revealed that there was a main effect of validity on $\mathrm{N} 1$ at $300 \mathrm{~ms} \mathrm{SOA}(F(1,14)=5.246, P=0.038)$. Grandaveraged ERPs for valid and invalid trials at parietal, temporal and occipital electrodes ipsilateral and contralateral to the target location are shown in Fig. 7 for the $300 \mathrm{~ms}$ SOA. The N1 amplitude was larger for validly cued targets than for invalidly cued targets at ipsilateral sites, as indicated by the significant validity $\mathrm{x}$ laterality interaction $(F(1,14)=8.544, P=0.011)$ and by the significant effect of validity at ipsilateral sites $(F(1,14)=12.479, P=0.003)$.

\section{Figure 7}

There were no significant differences between valid and invalid trials at 100, 500 or $700 \mathrm{~ms}$ SOAs, although significant electrode $\mathrm{x}$ validity interactions for the $100 \mathrm{~ms} \operatorname{SOA}(F(5,70)=5.690, P=0.005$, $\varepsilon=0.478)$ and for the $500 \mathrm{~ms} \operatorname{SOA}(F(5,70)=8.130, P=0.001, \varepsilon=0.469)$ were detected. Additional analysis showed that there were no significant effects of validity at any scalp location for the SOA of 
$500 \mathrm{~ms}$, and the difference between valid and invalid trials only reached statistical significance at the right temporal electrode for the SOA of $100 \mathrm{~ms}(F(1,14)=6.885, P=0.020)$.

\section{Discussion}

The objective of this study was to investigate the effects of the central and peripheral cueing on N1 amplitude and the time course of these effects.

The present data showed effects of validity on N1 with central cueing at 300 and $500 \mathrm{~ms}$ SOAs, with variations in the topographical distribution of these effects as a function of cue-to-target SOA. N1 amplitude was enlarged for valid trials $300 \mathrm{~ms}$ after cue onset over right parietal, occipital and temporal scalp locations to ipsilaterally presented stimuli. When SOA increased to $500 \mathrm{~ms}$, there was a main effect of validity on N1, with enhanced N1 amplitudes for valid targets over parietal, left temporal and left occipital scalp locations. These ERP results are consistent with the facilitation on RT in valid as opposed to invalid trials at these SOAs.

In this way, as shown in Fig. 1, the time course of the central cueing effects on N1 amplitude revealed by the present results appears to indicate that the facilitatory effect developed over time, reaching the highest value $500 \mathrm{~ms}$ after cue onset. The scarcity of studies, to our knowledge, which investigate the effects of central cues on N1 component by a systematical variation of SOA, makes difficult to evaluate the consistency of the present findings. Enhanced N1 amplitudes to valid trials (relative to neutral trials) under central cueing conditions have been reported by Luck et al. (1994) for SOAs varying randomly between 200 and $500 \mathrm{~ms}$, which is consistent with the N1 validity effect at medium SOAs found in the present experiment. However, this study did not allow to assess the time course of these effects or the optimal SOA. The time course of the effects of spatial orienting elicited by central cueing on ERPs was studied by Eimer (2000), who found enhanced negativities for valid trials relative to invalid trials with a long cue- target interval (700 ms), but not with a short interval (200 ms). In the present study, the systematic variation of SOA allowed us to observe that the effect of attentional orienting elicited by central cueing on $\mathrm{N} 1$ was present at a SOA of $300 \mathrm{~ms}$ over right posterior sites when targets were presented ipsilaterally, but not at $100 \mathrm{~ms}$ SOA (in which the effect was inverted). These results suggest that it may take a few hundred milliseconds (at least $300 \mathrm{~ms}$ in this experiment) in order that the effects of voluntary attentional shifts on the level of processing reflected by N1 can be observed. Additional studies manipulating the time between cue and target by closer intervals are required to characterize in more detail the time course of these effects. Furthermore, further research including neutral (or even 
non-cue) conditions in addition to valid and invalid ones, will shed some light on the inversion effect observed at $100 \mathrm{~ms}$ SOA.

Regarding the results obtained at $700 \mathrm{~ms}$ SOA, as shown in Fig. 1, there was a tendency for enhanced N1 amplitude for valid relative to invalid trials, which did not become statistically significant. The conclusions about the present results at $700 \mathrm{~ms}$ SOA must be cautions because of the enhancement of $\mathrm{N} 1$ amplitude to attended stimuli following valid central cues has been a common finding in the prior literature (Hillyard et al., 1994; Mangun and Hillyard, 1991). The data variability observed at this SOA condition (see Table 1) could prevent the presence of a significant effect in this experiment. Nevertheless, the factors mediating the attention effects on early perceptual processing are still debated. Some authors have reported about the influence of the response relevance of stimuli at unattended locations (Eimer, 1994b, 1996, 1998; see also Nobre et al., 2000). More recently, Handy and Mangun (2000) provided evidence that perceptual load can also affect early spatial selection. The present results suggest that the cue-to-target SOA may represent another factor influencing in the magnitude of this effect. On the other hand, the present data are partially consistent with prior works that have found a N1 validity effect ipsilaterally distributed (Eimer, 1993, 1994b, 1996; Mangun and Hillyard, 1991), although this effect was only revealed for the $300 \mathrm{~ms}$ SOA in the present study.

Additionally, the present results showed differential modulations of P1 and N1 components by attention, given that the effect of validity was not significant at the P1 level in this study (Doallo et al., 2004). Dissociations between the P1 and N1 attention effects have been reported from different visuospatial attention tasks (Heinze and Mangun, 1995; Heinze et al., 1990; Luck and Hillyard, 1995; Luck et al., 1990; Mangun and Hillyard, 1991). These dissociations suggest that these two ERPs components reflect different attentional processes (for review, see Luck, 1995). Luck et al. (1994), in a spatial cueing study, found reduced P1 amplitudes to invalid trials compared to neutral trials, but enhanced N1 amplitudes to valid trials relative to neutral trials. These authors suggested that P1 attention effect may reflect a mechanism that suppresses information from unattended locations, whereas the N1 attention effect may reflect a mechanism that produces an enhancement of processing of stimuli at the attended location. Other studies have reported that the N1 effect appears to be only present when subjects make a discrimination task at the attended location (Mangun and Hillyard, 1991). On the basis of these lines of evidence, Luck (1995) proposed that the N1 effect reflects the application of a discrimination process to attended stimuli. The present data are in line with previous evidence showing that the voluntary allocation of attention facilitates the discriminative processing at the attended location. 
With informative-peripheral cueing, the amplitude of N1 was larger for validly cued targets than for invalidly cued targets with an SOA of $300 \mathrm{~ms}$, but this validity effect was absent at 100, 500 and 700 ms SOAs. This effect presented an ipsilateral distribution and it was lateralized to the left hemisphere. Previous studies using SOAs around $300 \mathrm{~ms}$ have reported diverse results: Fu et al. (2001) found a validity effect on N1 over ipsilateral temporal and occipital regions, but a smaller contralateral N1 in valid than in invalid trials; Eimer (2000) found an enhanced negativity for valid trials, starting around $150 \mathrm{~ms}$ post-stimulus over occipital and parietal sites with a cue-target interval of $200 \mathrm{~ms}$, whereas Anllo-Vento (1995) did not find significant differences between valid and invalid trials in P1/N1 with an SOA of $200 \mathrm{~ms}$. The results of the present study showed no significant differences between valid and invalid trials when an SOA of $100 \mathrm{~ms}$ was used, but a significant effect of cue validity on N1 was present when SOA increased to $300 \mathrm{~ms}$. However, we did not find effects of cue validity on N1 with long SOAs previously reported by other authors (Eimer, 1994a; Hillyard et al., 1994).

With uninformative-peripheral cues, there was also a main validity effect on N1 with an SOA of 300 $\mathrm{ms}$, ipsilaterally distributed. A significant difference between valid and invalid trials was also found at the right temporal electrode at $100 \mathrm{~ms} \mathrm{SOA}$ and there were no effects with the two longest SOAs. To our knowledge, there are no studies that examined the effects of uninformative-peripheral cues with short SOAs. Previous studies using long SOAs found validity effects in one case (Eimer, 1994a, at parietal sites with an SOA of $700 \mathrm{~ms}$ ) and no effects in other experiments (McDonald et al., 1999, with SOAs of 500-700 and 900- $1100 \mathrm{~ms}$ ).

Therefore, the present data showed that peripheral cues affected optimally to the level of processing reflected by N1 $300 \mathrm{~ms}$ after cue onset, for both informative and uninformative cues, although it could be also observed a N1 validity effect at $100 \mathrm{~ms}$ SOA for uninformative cues at the right temporal electrode. In our previous study (Doallo et al., 2004), we observed markedly different effects of these peripheral cues on P1 component. The optimal cue facilitatory effects on the level of processing reflected by $\mathrm{P} 1$ were detected at $100 \mathrm{~ms}$ SOA for both informative and uninformative cues; however, P1 amplitude was reduced for validly cued targets at 300, 500 and $700 \mathrm{~ms}$ SOAs with uninformativeperipheral cueing, and at $500 \mathrm{~ms}$ SOA with informative-peripheral cueing. These results reveal a clear dissociation of the peripheral cueing effects on P1 and N1 components. Taken together, these results show that reflexive/exogenous attentional orienting triggered by a peripheral cue modulated optimally the early visual processing at a level of processing indexed by P1 for a short period after presentation of the cue (100 ms), a facilitatory effect also observed in behavioral execution. The pattern of results is less clear at longer SOAs, where the electrophysiological difference between valid and invalid trials with peripheral cues seemed to be uncoupled from overt behavior. Effects of cue validity by 
informative-peripheral cueing, associated with RT benefi were observed at the level of processing reflected by the N1 component with an SOA of $300 \mathrm{~ms}$. Two findings prevent to conclude that this effect is due to a fully endogenous mechanism elicited by the predictive character of the cue. First, if this $\mathrm{N} 1$ effect was reflecting the effects of a voluntary orienting process to the cued location, validity effects on N1 would have been also expected at longer SOAs. Second, this N1 effect was also observed for uninformative-peripheral cues. A similar pattern of results was reported by Eimer (1994a), who found a validity effect on $\mathrm{N} 1$ at parietal sites with informative- and uninformative-peripheral cueing, associated only with RT benefits for valid trials with informative cues. This author postulated that this validity effect might reflect a processing advantage for validly cued stimuli, which might be present even when the cue is not informative, and that these ERPs effects may be uncoupled from overt behavior (see Eimer, 1998 for an additional explanation of the parietal N1 effect).

It must be noted that, in the present study, the N1 validity effect at $300 \mathrm{~ms}$ SOA was lateralized to the left hemisphere with informative-peripheral cues but not with uninformative-peripheral cues, which might be reflecting functional differences in the underlying attentional mechanisms depending on cue informativeness. Our data appears to indicate that the reflexive attention can influence the level of processing indexed by the $\mathrm{N} 1$ component. If the $\mathrm{N} 1$ validity effect reflects a facilitation of discriminative processing, it is plausible to propose from the present data that these effects can be also observed as a result of exogenous attentional orienting, at least under some circumstances. Moreover, it has been proposed that there are functional differences between central and peripheral cueing (Eimer, 1994a). This author, using peripheral cueing, also observed N1 validity effects when the response was dependent on target location, in contrast with previous central cueing studies, which found a N1 validity effect only when subjects were required to perform a discrimination task at the cued location (Mangun and Hillyard, 1991). Eimer (1994a) proposed that, with peripheral cues, 'the process reflected by the N1 validity effect may be activated regardless of specific task demands'.

It is not possible to determine completely from the present data the significance of the present N1 modulations by peripheral cueing. Our data simply provide evidence about differential characteristics in the time course of the effects of central and peripheral cues on posterior N1 component. Peripheral cues (informative and uninformative) elicited optimal effects of cue validity on N1 $300 \mathrm{~ms}$ after cue onset, whereas valid central cues led to a more sustained effect on N1, with later optimal effects, at 500 ms SOA. These results suggest that endogenous attentional allocation in response to central cues resulted in a more sustained validity effect on $\mathrm{N} 1$, as compared with the more transitory activation of the process reflected by the $\mathrm{N} 1$ validity effect in this peripheral cueing task. 
However, to assess more completely the present findings, it is necessary to take into account the following factor. The different cue-to-target SOAs were administered blockwise in order to evaluate systematically the time course of the validity effects of central and peripheral cueing. The rationale of the present experiment was that the systematical variation of the cue-to-target SOA would allow to obtain different attentional effects due to the different time course of the endogenous and exogenous orienting mechanisms. Thus, the differences between SOAs were interpreted as reflecting the time course of validity effects. However, an alternative explanation may be also raised. It is possible that different SOAs led to different states of arousal or expectation instead of a different time course of the attentional processes involved. Moreover, it is possible that a randomized variation of SOAs had elicited a different processing. For instance, it has been provided ERP evidence (Li et al., 2003) about a faster and more effective visual processing under constant SOA conditions as compared with random SOA conditions. It would be interesting to compare in future experiments central and peripheral cueing conditions using blocked and randomized order of SOAs, which would allow to assess the effects of constant and random conditions on early visual processing.

Another methodological factor that it is necessary to mention is the differential length among the cueing stimuli (central and peripheral), which may be influencing the observed effects in the present study.

In summary, the results reported here show that the pattern of the modulation effects of central and peripheral cues on the processing occurring at the N1 time is complex, as it changes when the cue-totarget SOA is manipulated. So, the lines of interpretation advanced here require new studies manipulating this variable in within-subjects designs in order to confirm the results and fully characterize the involved processes.

\section{Acknowledgements}

This study was supported by Spain's Ministerio de Ciencia y Tecnología (grant BSO2000-0041) and by the Galician Secretaría Xeral de I C D (PGIDT00P-SI211102PR, PGIDT01PXI21101PN). We thank to Neuro-behavioral Systems, Inc. for the free software Presentation, used to design and administer the stimulation paradigm. The authors are grateful to two anonymous reviewers for their valuable comments on an earlier version of the paper. 


\section{Appendix. Procedure to correct for possible ERP overlapping}

To avoid overlapping of the ERPs elicited by cues and targets in the shortest SOA conditions, a correction was applied as follows.

Let VR(cue,tar,soa,loc; $t$ ) be the averaged ERP recorded at electrode location loc for each cue, target and SOA combination (six values for cue: central right-left, peripheral informative right-left, peripheral non-informative right-left; 4 for target: valid right-left, invalid right-left; four for SOA: 100, $300,500,700 \mathrm{~ms}$ ); the variable ' $t$ ' denotes the time (these functions are assumed throughout this paper to be discrete functions of time). Let us also write $\mathrm{VC}(\mathrm{cue}, \mathrm{loc} ; t)$ for the averaged ERP triggered by a given cue at the electrode location loc, and VT(cue,tar,soa,loc; $t$ ) for the averaged ERP elicited by a given target after the corresponding cue. Assuming, as in the Adjar technique (Woldorff, 1993), that both VC and VT are time-invariant and that the electric fields of overlapping ERPs add linearly, the averaged recorded ERP (time-locked to the target), VR, is given by

$$
\text { VR(cue, tar, soa, loc; t })=\text { VT }(\text { cue }, \text { tar, soa, loc; } t)+\text { VC }(\text { cue }, \text { loc; } t+\text { soa })
$$

Writing Eq. (1) we implicitly assume, apart from system linearity and time-invariance, that:

(a) only first-order overlapping effects from the immediately previous cue are taken into account (i.e. no overlapping effects from more remote previous nor immediate subsequent cues and targets are of interest, which is a reasonable assumption since the intertrial intervals were as long as $1800 \mathrm{~ms}$ ); and

(b) the shape of the cue ERP (VC) is independent of the SOA (an assumption supported by the fact that the recorded cue response is noticeably equal for all SOAs during the time slot of the corresponding SOA).

Filtering the VR waveform to obtain the desired VT requires having a good estimate of the overlapping response VC. In ERP experiments with only short SOAs and short intertrial intervals, interstimulus jittering is essential in order to enable the application of procedures for estimating VC like those used in the Adjar level 1 technique. Indeed, the combination of jittering and grand-averaging is what allows us to obtain in these cases a reasonable estimate of the overlapping previous responses and carry out the overlap removal once the previous event distributions are known. However, in our experiment we have recorded $\mathrm{VC}$ waveforms for each cue condition (including the cue hemifield) with a long SOA (700 ms) which can reasonably be assumed not to overlap with the subsequent target response. According to (b), these averaged waveforms [denoted henceforth by $\mathrm{VC} 700(\mathrm{cue}, \mathrm{loc} ; t)$ ] give us a reasonably good estimate of the VC ERPs for the $700 \mathrm{~ms}$ following the corresponding cue, whatever 
the SOA may be. We have separately computed the VC700 for each cue condition at each relevant electrode location. Then, for each (cue, tar, soa, loc) condition, filtering can be done by subtracting

$$
\text { VT(cue, tar, soa, loc; t })=\text { VR(cue, tar, soa, loc; t })-V_{700}(\text { cue, loc; } t+\text { soa })(2)
$$

The range of validity of Eq. (2) extends to an elapsed time of [700 ms - SOA] since the stimulus onset. Eq. (2) is a particular case of overlap removal when the previous-event normalized distribution approaches a Kronecker-delta in the discrete time domain and the VC waveforms are known.

In our case the absence of jitter for each nominal SOA does not allow the low-pass filtering of the VC contribution to the recorded ERP, so there is no gain in implementing recursive procedures such as Adjar level-2. Furthermore, using such a recursive procedure to estimate the VC contribution does not seem necessary, since the required data can be obtained directly from the VC700 records.

\section{Acknowledgements}

This study was supported by Spain's Ministerio de Ciencia y Tecnología (grant BSO2000-0041) and by the Galician Secretaría Xeral de I + D (PGIDT00PSI211102PR, PGIDT01PXI21101PN). We thank to Neurobehavioral Systems, Inc. for the free software Presentation, used to design and administer the stimulation paradigm. The authors are grateful to two anonymous reviewers for their valuable comments on an earlier version of the paper.

\section{References}

Anllo-Vento L. Shifting attention in visual space: the effects of peripheral cueing on brain cortical potentials. Int J Neurosci 1995;80:353-70.

Briand KA, Klein RM. Is Posner's 'beam' the same as Treisman's 'glue'? On the relation between visual orienting and feature integration theory. J Exp Psychol Hum Percept Perform $1987 ; 13: 228-41$.

Doallo S, Lorenzo-López L, Vizoso C, Rodríguez Holguín S, Amenedo E, Bará S, Cadaveira F. The time course of the effects of central and peripheral cues on visual processing: an event-related potentials study. Clin Neurophysiol 2004;115:199-210.

Eimer M. Spatial cueing, sensory gating and selective response preparation: an ERP study on visuospatial orienting. Electroencephalogr Clin Neurophysiol 1993;88:408-20.

Eimer M. An ERP study on visual spatial priming with peripheral onsets. Psychophysiology 1994a;31:154-63. 
Eimer M. 'Sensory gating' as a mechanism for visuospatial orienting: electrophysiological evidence from trial-by-trial cuing experiments. Percept Psychophys 1994b;55:667-75.

Eimer M. ERP modulations indicate the selective processing of visual stimuli as a result of transient and sustained spatial attention. Psychophysiology 1996;33:13-21.

Eimer M. Mechanisms of visuospatial attention: evidence from event-related brain potentials. Visual Cognit 1998;5:257-86.

Eimer M. The time course of spatial orienting elicited by central and peripheral cues: evidence from event-related brain potentials. Biol Psicol 2000;53:253-8.

Fu S, Fan S, Chen L, Zhuo Y. The attentional effects of peripheral cueing as revealed by two eventrelated potential studies. Clin Neurophysiol 2001;112:172-85.

Gómez CM, Clark VP, Fan S, Luck SJ, Hillyard SA. Sources of attention-sensitive visual event-related potentials. Brain Topogr 1994;7:41-51.

Handy TC, Mangun GR. Attention and spatial selection: electrophysiological evidence for modulation by perceptual load. Percept Psychophys 2000;62:175-86.

Heinze HJ, Mangun GR. Electrophysiological signs of sustained and transient attention to spatial locations. Neuropsychologia 1995;33: 889-908.

Heinze HJ, Luck SJ, Mangun GR, Hillyard SA. Visual event-related potentials index focused attention within bilateral stimulus arrays. I. Evidence for early selection. Electroencephalogr Clin Neurophysiol 1990;75:511-27.

Heinze HJ, Mangun GR, Burchert W, Hinrichs H, Scholz M, Münte TF, Gös A, Scherg M, Johannes S, Hundeshagen H, Gazzaniga MS, Hillyard SA. Combined spatial and temporal imaging of brain activity during visual selective attention in humans. Nature 1994;372:543-6.

Hillyard SA, Luck SJ, Mangun GR. The cuing of attention to visual field locations: analysis with ERP recordings. In: Heinze HJ, Münte TF, Mangun GR, editors. Cognitive electrophysiology. Boston: Birkhäuser; 1994. p. 1-25.

Hillyard SA, Vogel EK, Luck SJ. Sensory gain control (amplification) as a mechanism of selective attention: electrophysiological and neuroimaging evidence. In: Humphreys GW, Duncan J, Treisman A, editors. Attention, space and action. Studies in cognitive neuroscience. New York: Oxford University Press; 1999. p. 31-53.

Hopfinger JB, Mangun GR. Reflexive attention modulates processing of visual stimuli in human extrastriate cortex. Psychol Sci 1998;9:441-7. Hopf J-M, Vogel E, Woodman G, Heinze H-J, Luck SJ. Localizing visual discrimination processes in time and space. J Neurophysiol 2002;88:2088-95.

Jonides J. Voluntary versus automatic control over the mind's eye's movement. In: Long JB, Baddeley $\mathrm{AD}$, editors. Attention and performance IX. Hillsdale, NJ: Lawrence Erlbaum Associates; 1981. p. 187-203.

Li M, Kuroiwa Y, Omoto S, Hotta S, Suzuki Y, Kamitani T, Koyano S, Segawa H. The effect of stimulus-onset asynchrony on human visual event-related potentials during simple and choice reaction paradigms under constant or random conditions. Neurosci Lett 2003;345:109-12.

Luck SJ. Multiple mechanisms of visual-spatial attention: recent evidence from human electrophysiology. Behav Brain Res 1995;71:113-23.

Luck SJ, Hillyard SA. The role of attention in feature detection and conjunction discrimination: an electrophysiological analysis. Int J Neurosci 1995;80:281-97. 
Luck SJ, Heinze HJ, Mangun GR, Hillyard SA. Visual event-related potentials index focused attention within bilateral stimulus arrays. II. Functional dissociation of P1 and N1 components. Electroencephalogr Clin Neurophysiol 1990;75:528-42.

Luck SJ, Hillyard SA, Mouloua M, Woldorff MG, Clark VP, Hawkins HL. Effects of spatial cuing on luminance detectability: psychophysical and electrophysiological evidence for early selection. J Exp Psychol Hum Percept Perform 1994;20:887-904.

Mangun GR, Hillyard SA. Electrophysiological studies of visual selective attention in humans. In: Scheibel AB, Wechsler A, editors. The neurobiological foundations of higher cognitive function. New York: Guilford Press; 1990. p. 271-95.

Mangun GR, Hillyard SA. Modulations of sensory-evoked brain potentials indicate changes in perceptual processing during visual-spatial priming. J Exp Psychol Hum Percept Perform 1991;17:1057-74.

Mangun GR, Hansen JC, Hillyard SA. The spatial orienting of attention: sensory facilitation or response bias?. In: Johnson R, Rohrbaugh JW, Parasuraman R, editors. Current trends in event-related potential research. Amsterdam: Elsevier; 1987. p. 118-24.

Mangun GR, Hillyard SA, Luck SJ. Electrocortical substrates of visual selective attention. In: Meyer D, Kornblum S, editors. Attention and performance XIV. Cambridge, MA: The MIT Press; 1993. p. 219-43. Mangun GR, Hopfinger JB, Kussmaul CL, Fletcher EM, Heinze HJ. Covariations in ERP and PET measures of spatial selective attention in human extrastriate visual cortex. Hum Brain Mapp 1997;5:273-9.

Martínez A, Anllo-Vento L, Sereno MI, Frank LR, Buxton RB, Dubowitz DJ, Wong EC, Hinrichs H, Heinze HJ, Hillyard SA. Involvement of striate and extrastriate visual cortical areas in spatial attention. Nat Neurosci 1999;2:364-9.

McDonald JJ, Ward LM, Kiehl KA. An event-related brain potential study of inhibition of return. Percept Psychophys 1999;61:1411-23.

Müller HJ, Rabbitt PMA. Reflexive and voluntary orienting of visual attention: time course of activation and resistance to interruption. J Exp Psychol Hum Percept Perform 1989;15:315-30.

Nobre AC, Sebestyen GN, Miniussi C. The dynamics of shifting visuospatial attention revealed by event-related potentials. Neuropsychologia 2000;38:964-74.

Pesce C, Böel R. Focusing of visuospatial attention. Electrophysiological evidence from subjects with and without attentional expertise. J Psychophysiol 2001;15:256-74.

Posner MI. Orienting of attention. Q J Exp Psychol 1980;32:3-25.

Posner MI, Nissen MK, Ogden WC. Attended and unattended processing modes: the role of set for spatial location. In: Pick HL, Saltzman E, editors. Modes of perceiving and processing information. Hillsdale, NJ: Lawrence Erlbaum Associates; 1978. p. 137-57.

Vogel EK, Luck SJ. The visual N1 component as an index of a discrimination process. Psychophysiology 2000;37:190-203.

Woldorff MG. Distorsion of ERP averages due to overlap from temporally adjacent ERPs: analysis and correction. Psychophysiology 1993;30: 98-119. 


\section{Tables}

Table 1. Mean values of N1 amplitude (in $\mu \mathrm{V}$ ) to valid and invalid trials at parietal, temporal and occipital scalp locations contralateral and ipsilateral to the target location in the informative-central cueing condition

\begin{tabular}{|c|c|c|c|c|c|}
\hline \multirow[t]{2}{*}{ SOA } & \multirow[t]{2}{*}{ Electrode } & \multicolumn{2}{|l|}{ Contralateral } & \multicolumn{2}{|l|}{ Ipsilateral } \\
\hline & & Valid & Invalid & Valid & Invalid \\
\hline \multirow[t]{6}{*}{100} & PL & $-2.39(2.93)$ & $-4.48(3.24)$ & - $1.96(1.64)$ & $-3.12(3.27)$ \\
\hline & PR & $-2.18(2.95)$ & $-3.64(3.66)$ & $-2.42(2.52)$ & $-3.01(2.52)$ \\
\hline & T5 & $-1.46(3.08)$ & $-3.41(2.45)$ & $-1.25(1.11)$ & $-2.01(2.67)$ \\
\hline & T6 & $-0.81(2.73)$ & $-1.67(2.75)$ & $-1.55(2.28)$ & $-2.15(2.39)$ \\
\hline & OL & $-1.29(3.50)$ & $-3.60(3.47)$ & $-0.87(1.39)$ & $-2.00(3.26)$ \\
\hline & OR & $0.38(3.24)$ & $-0.85(3.18)$ & $-0.87(2.57)$ & $-1.29(2.84)$ \\
\hline \multirow[t]{6}{*}{300} & PL & $-3.28(3.91)$ & $-2.40(3.51)$ & $-1.81(2.61)$ & $-2.09(2.58)$ \\
\hline & PR & $-3.16(3.84)$ & $-3.55(5.49)$ & $-3.16(3.04)$ & 0.15 (1.99) \\
\hline & T5 & $-2.21(3.38)$ & $-1.48(3.69)$ & $-0.95(2.60)$ & $-1.38(3.31)$ \\
\hline & T6 & $-1.12(3.73)$ & $-2.11(4.65)$ & $-1.56(3.00)$ & $0.97(1.93)$ \\
\hline & OL & $-2.59(3.98)$ & - $1.65(3.69)$ & $-0.64(3.09)$ & $-1.38(3.13)$ \\
\hline & OR & $-0.81(3.80)$ & $-1.78(5.21)$ & $-1.34(3.18)$ & $1.32(2.30)$ \\
\hline \multirow[t]{6}{*}{500} & PL & - $7.09(4.58)$ & $-5.50(3.85)$ & $-4.69(3.49)$ & $-2.85(2.83)$ \\
\hline & PR & $-7.30(3.59)$ & $-4.90(3.69)$ & $-5.35(3.04)$ & $-4.54(3.56)$ \\
\hline & T5 & $-6.08(4.10)$ & $-4.92(3.52)$ & $-3.80(3.56)$ & $-2.52(2.62)$ \\
\hline & T6 & $-5.62(3.32)$ & $-4.41(3.66)$ & $-4.25(3.15)$ & $-3.77(3.32)$ \\
\hline & OL & $-6.66(4.67)$ & $-5.20(3.69)$ & $-4.14(3.96)$ & $-2.62(2.63)$ \\
\hline & OR & $-5.23(3.78)$ & $-3.34(4.31)$ & $-4.38(3.25)$ & $-3.60(3.25)$ \\
\hline \multirow[t]{6}{*}{700} & PL & $-4.38(3.46)$ & $-3.64(4.11)$ & $-2.60(2.66)$ & $-0.72(4.51)$ \\
\hline & PR & $-5.08(3.47)$ & $-3.61(5.97)$ & $-2.61(2.32)$ & $-1.68(3.35)$ \\
\hline & T5 & $-3.29(3.37)$ & - $3.07(4.38)$ & $-1.60(2.83)$ & $-0.09(4.51)$ \\
\hline & T6 & $-3.34(3.74)$ & $-2.73(5.93)$ & $-1.22(2.29)$ & $-0.88(2.80)$ \\
\hline & $\mathrm{OL}$ & $-3.39(3.99)$ & $-3.07(4.75)$ & $-1.52(3.07)$ & $-0.21(4.60)$ \\
\hline & OR & $-2.67(3.64)$ & $-1.94(6.20)$ & $-1.02(2.76)$ & $-0.34(3.55)$ \\
\hline
\end{tabular}

Standard deviations are in parentheses. 
Table 2. Mean values of $\mathrm{N} 1$ amplitude (in $\mu \mathrm{V}$ ) to valid and invalid trials at parietal, temporal and occipital scalp locations contralateral and ipsilateral to the target location in the informative-peripheral cueing condition

\begin{tabular}{|c|c|c|c|c|c|}
\hline \multirow[t]{2}{*}{$\mathrm{SOA}$} & \multirow[t]{2}{*}{ Electrode } & \multicolumn{2}{|l|}{ Contralateral } & \multicolumn{2}{|l|}{ Ipsilateral } \\
\hline & & $\overline{\text { Valid }}$ & Invalid & Valid & Invalid \\
\hline \multirow[t]{6}{*}{100} & PL & $-6.01(4.93)$ & $-6.95(4.76)$ & $-4.21(4.19)$ & $-3.78(4.08)$ \\
\hline & PR & $-5.52(4.98)$ & $-4.20(4.88)$ & $-4.58(3.74)$ & $-5.67(3.36)$ \\
\hline & $\mathrm{T} 5$ & $-5.56(5.09)$ & $-6.02(4.03)$ & $-3.88(3.85)$ & $-4.17(4.84)$ \\
\hline & T6 & $-4.94(4.75)$ & $-3.11(3.85)$ & $-3.77(3.35)$ & $-4.41(2.90)$ \\
\hline & OL & $-5.80(5.81)$ & $-6.54(4.91)$ & $-3.96(4.95)$ & $-4.25(4.73)$ \\
\hline & OR & $-4.52(4.72)$ & $-3.20(4.21)$ & $-3.89(4.11)$ & $-4.51(3.64)$ \\
\hline \multirow[t]{6}{*}{300} & PL & $-4.74(3.70)$ & $-4.36(4.30)$ & $-4.48(2.84)$ & $-1.50(3.54)$ \\
\hline & PR & $-4.30(4.65)$ & $-3.75(4.37)$ & $-4.35(2.66)$ & $-3.78(2.97)$ \\
\hline & T5 & $-2.78(2.97)$ & $-2.94(4.08)$ & $-2.61(2.57)$ & $-0.17(3.07)$ \\
\hline & T6 & $-2.29(3.92)$ & $-2.71(3.13)$ & $-2.48(2.21)$ & $-2.41(2.28)$ \\
\hline & OL & $-3.58(3.83)$ & $-3.73(4.60)$ & $-3.21(3.10)$ & $-0.69(3.71)$ \\
\hline & OR & $-1.67(4.15)$ & $-2.05(4.15)$ & $-2.48(2.54)$ & $-2.12(2.33)$ \\
\hline \multirow[t]{6}{*}{500} & PL & $-6.28(4.27)$ & $-5.76(4.64)$ & $-4.26(3.29)$ & $-3.09(3.29)$ \\
\hline & PR & $-5.57(3.87)$ & $-4.62(3.98)$ & $-4.60(3.10)$ & $-4.64(3.76)$ \\
\hline & T5 & $-4.63(3.49)$ & $-4.84(3.75)$ & $-2.63(2.89)$ & $-1.82(2.37)$ \\
\hline & T6 & $-3.50(3.31)$ & $-3.09(3.79)$ & $-2.62(2.57)$ & $-2.97(3.34)$ \\
\hline & $\mathrm{OL}$ & $-5.13(4.56)$ & $-4.33(5.04)$ & $-3.01(3.46)$ & $-2.02(2.50)$ \\
\hline & OR & $-2.76(3.65)$ & $-2.21(3.99)$ & $-2.51(3.14)$ & $-2.54(3.80)$ \\
\hline \multirow[t]{6}{*}{700} & PL & $-5.21(3.98)$ & $-5.47(4.10)$ & $-3.32(3.30)$ & $-3.56(3.17)$ \\
\hline & PR & $-5.11(4.58)$ & $-5.33(3.81)$ & $-3.48(2.97)$ & $-3.52(2.54)$ \\
\hline & T5 & $-4.16(3.49)$ & $-4.11(3.69)$ & $-1.97(2.46)$ & $-2.47(2.38)$ \\
\hline & T6 & $-3.42(3.79)$ & $-3.53(3.63)$ & $-2.15(2.47)$ & $-2.13(2.06)$ \\
\hline & $\mathrm{OL}$ & $-4.56(4.43)$ & $-4.13(4.76)$ & $-2.55(3.50)$ & $-2.85(3.02)$ \\
\hline & OR & $-2.67(4.20)$ & $-2.98(3.69)$ & $-1.67(3.23)$ & $-1.40(2.80)$ \\
\hline
\end{tabular}

Standard deviations are in parentheses.

\section{Post-print (final draft post-refereeing)}


Table 3. Mean values of $\mathrm{N} 1$ amplitude (in $\mu \mathrm{V}$ ) to valid and invalid trials at parietal, temporal and occipital scalp locations contralateral and ipsilateral to the target location in the uninformative-peripheral cueing condition

\begin{tabular}{clllll}
\hline \multirow{2}{*}{ SOA } & Electrode & Contralateral & & \multicolumn{2}{l}{ Ipsilateral } \\
\cline { 3 - 5 } \cline { 3 - 5 } & & Valid & Invalid & Valid & Invalid \\
\hline 100 & PL & $-5.30(4.65)$ & $-5.42(4.75)$ & $-4.17(4.20)$ & $-3.57(4.01)$ \\
& PR & $-5.52(4.20)$ & $-4.29(4.93)$ & $-4.31(4.11)$ & $-4.42(2.35)$ \\
& T5 & $-5.21(4.55)$ & $-4.30(3.83)$ & $-3.31(4.58)$ & $-4.03(4.14)$ \\
& T6 & $-4.88(4.30)$ & $-2.84(4.49)$ & $-4.28(3.98)$ & $-3.11(2.49)$ \\
& OL & $-5.50(5.55)$ & $-5.44(4.99)$ & $-3.78(5.25)$ & $-4.21(4.43)$ \\
300 & OR & $-4.45(4.65)$ & $-3.12(5.14)$ & $-3.93(4.64)$ & $-3.44(3.05)$ \\
& PL & $-5.17(3.51)$ & $-4.92(3.83)$ & $-3.97(3.06)$ & $-1.65(3.74)$ \\
& PR & $-3.84(4.31)$ & $-2.94(3.92)$ & $-4.32(3.19)$ & $-2.68(2.59)$ \\
& T5 & $-3.16(2.71)$ & $-3.56(3.87)$ & $-2.02(2.50)$ & $-0.40(3.50)$ \\
& T6 & $-2.00(3.81)$ & $-2.11(3.45)$ & $-2.85(2.30)$ & $-1.05(2.43)$ \\
& OL & $-3.56(4.04)$ & $-4.29(3.83)$ & $-2.57(3.13)$ & $-0.51(3.92)$ \\
& OR & $-1.35(4.10)$ & $-1.45(4.10)$ & $-2.42(2.73)$ & $-0.65(2.85)$ \\
& PL & $-5.90(4.32)$ & $-4.88(4.58)$ & $-3.58(3.62)$ & $-2.84(4.18)$ \\
& PR & $-4.82(4.50)$ & $-4.26(4.64)$ & $-3.63(2.79)$ & $-3.96(3.87)$ \\
& T5 & $-4.37(3.84)$ & $-4.00(3.82)$ & $-2.57(3.28)$ & $-1.49(3.31)$ \\
& T6 & $-3.22(3.80)$ & $-3.27(3.90)$ & $-1.93(2.52)$ & $-2.55(3.31)$ \\
& OL & $-4.87(4.84)$ & $-4.58(4.82)$ & $-2.64(3.87)$ & $-2.11(3.94)$ \\
& OR & $-2.21(4.29)$ & $-2.25(4.26)$ & $-1.31(2.78)$ & $-2.31(3.58)$ \\
& PL & $-5.51(4.75)$ & $-4.71(4.89)$ & $-2.99(4.07)$ & $-1.90(4.06)$ \\
& PR & $-4.07(4.72)$ & $-3.54(4.70)$ & $-3.77(3.34)$ & $-3.87(3.51)$ \\
& T5 & $-3.83(3.86)$ & $-3.66(4.23)$ & $-1.37(3.40)$ & $-0.77(3.28)$ \\
& T6 & $-2.75(4.39)$ & $-2.38(4.25)$ & $-2.29(2.96)$ & $-2.74(3.13)$ \\
& OL & $-4.40(5.09)$ & $-4.07(5.19)$ & $-1.55(4.02)$ & $-1.02(3.65)$ \\
& OR & $-2.07(4.74)$ & $-1.54(4.64)$ & $-1.76(3.53)$ & $-2.31(3.42)$ \\
\hline
\end{tabular}

Standard deviations are in parentheses. 


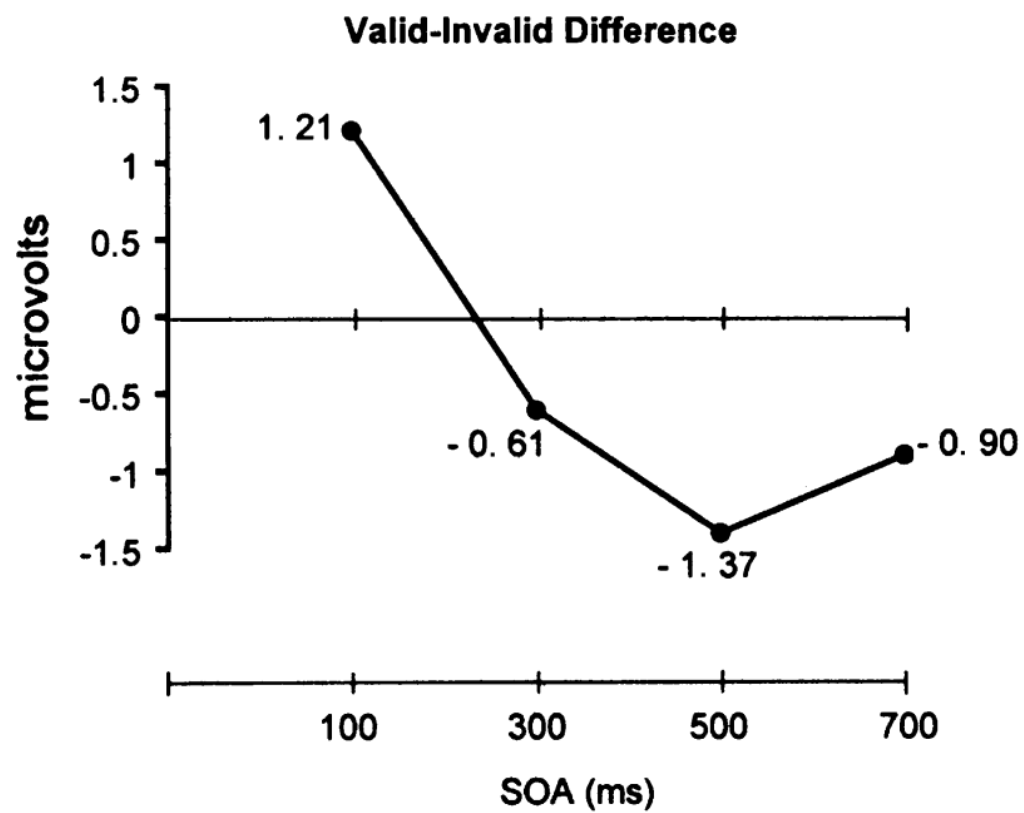

Figure 1. The time course of the N1 validity effect in the informative-central cueing condition: valid-invalid differences across SOAs.

\section{Post-print (final draft post-refereeing)}


INFORMATIVE-CENTRAL CUEING (SOA $100 \mathrm{~ms}$ ) IPSILATERAL

CONIRALATERAL

PL

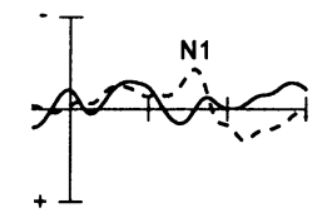

T5

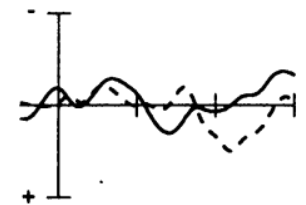

OL

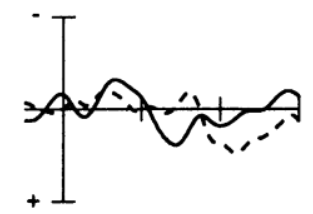

PR

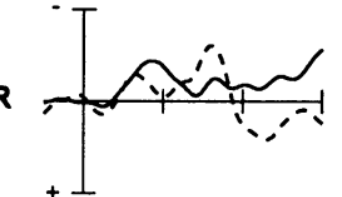

T6

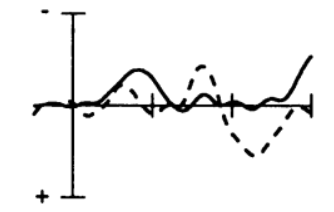

PL
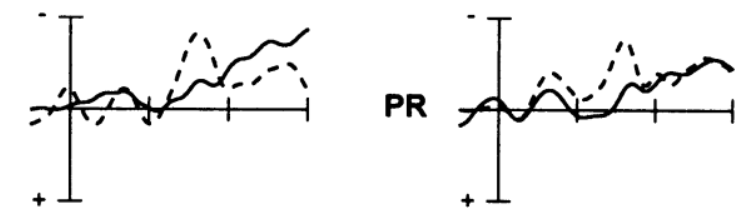

T5

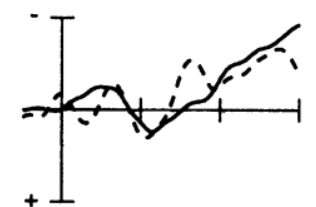

T6
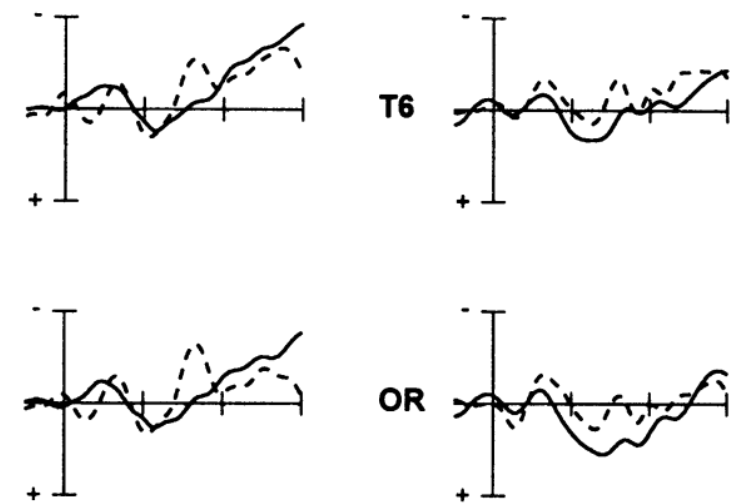

OR

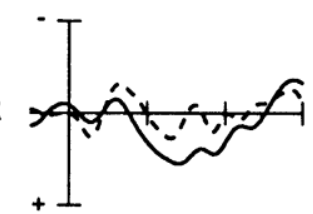

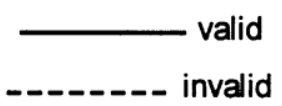

valid

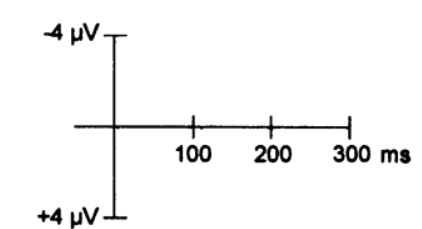

Figure 2. Grand-averaged ERPs for valid and invalid trials at parietal, temporal and occipital electrodes ipsilateral and contralateral to the target location in the informative-central cue condition for the $100 \mathrm{~ms}$ SOA.

\section{Post-print (final draft post-refereeing)}




\section{INFORMATIVE-CENTRAL CUEING (SOA $500 \mathrm{~ms}$ )}

IPSILATERAL

CONTRALATERAL

PL

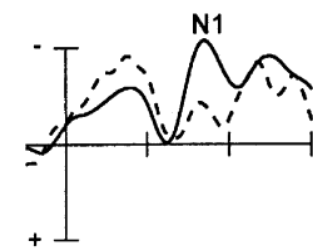

T5

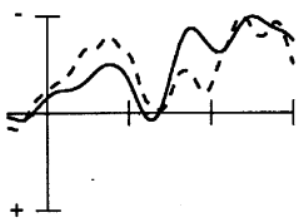

OL

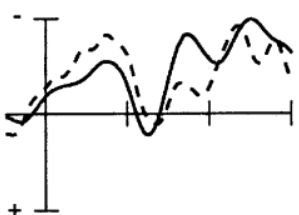

PR

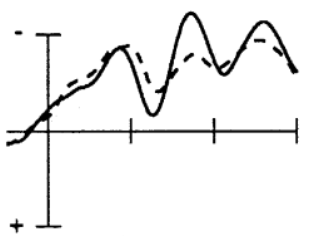

T6

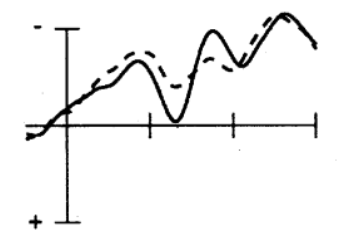

OR

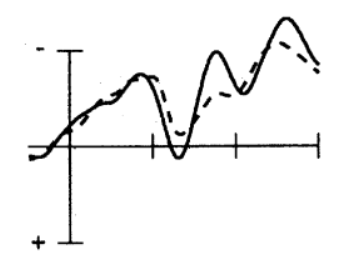

PL

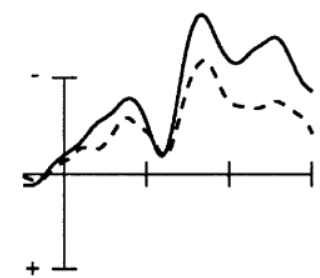

T5

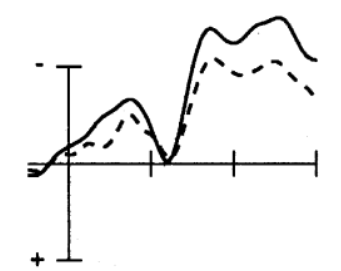

PR

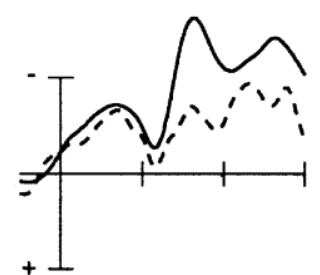

T6

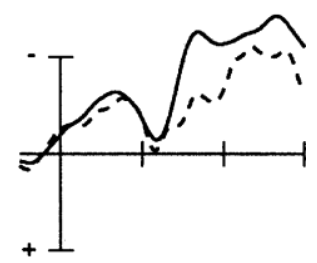

$\mathrm{OL}$

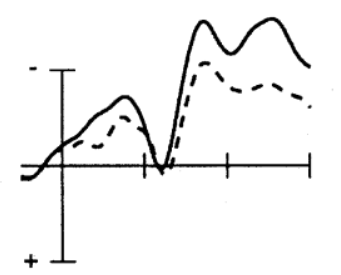

OR

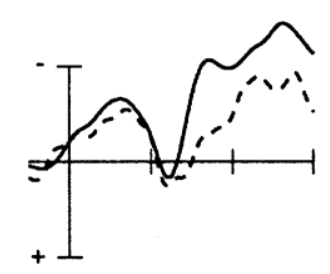

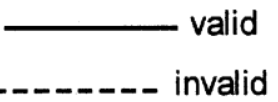

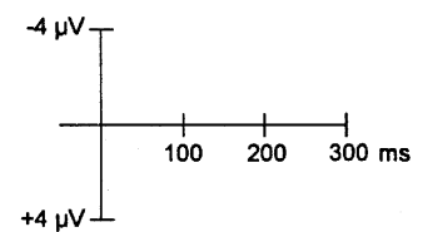

Figure 3. Grand-averaged ERPs for valid and invalid trials at parietal, temporal and occipital electrodes ipsilateral and contralateral to the target location in the informative-central cue condition for the $500 \mathrm{~ms}$ SOA. 
INFORMATIVE-CENTRAL CUEING (SOA $300 \mathrm{~ms}$ )

IPSILATERAL

CONIRALATERAL

PL<smiles>CCCCC1CCCCC12CCCC2</smiles>

T5

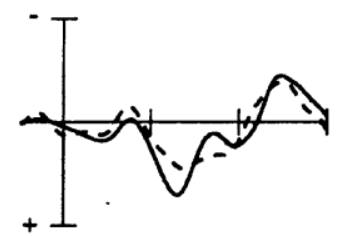

OL

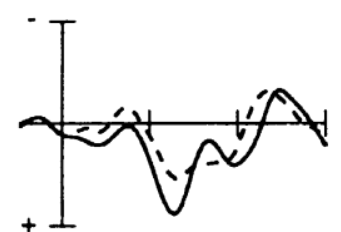

PR

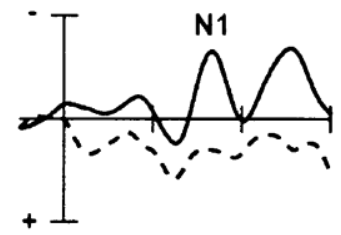
T6

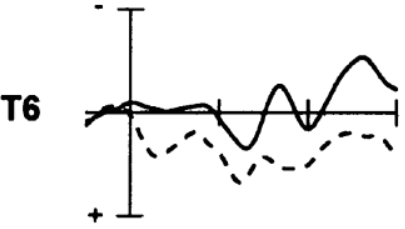

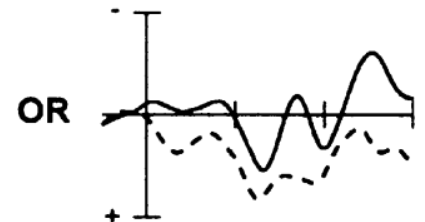

PL<smiles>CCC(C)C=C1CCCC1N1CCCC1</smiles>

T5

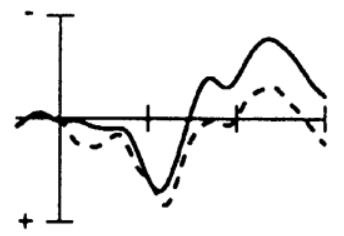

OL

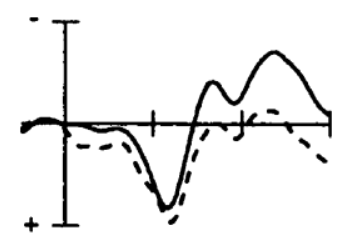

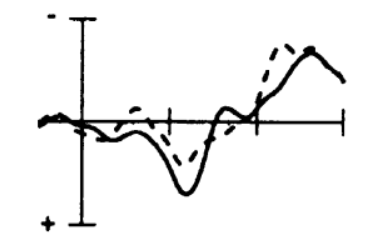

PR
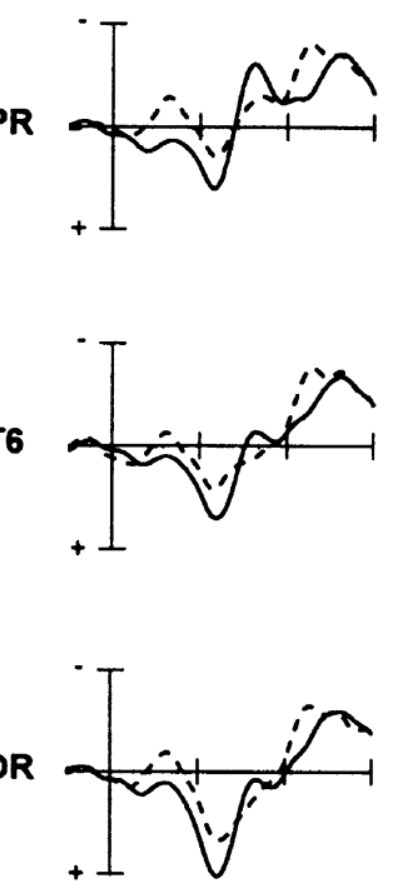

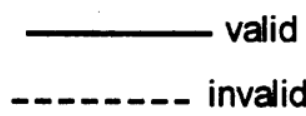

\section{valid}

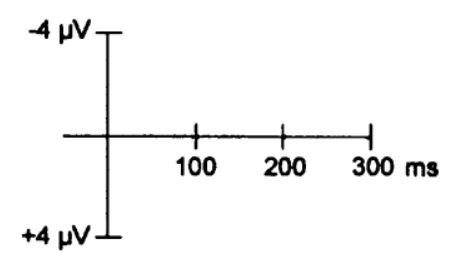

Figure 4. Grand-averaged ERPs for valid and invalid trials at parietal, temporal and occipital electrodes ipsilateral and contralateral to the target location in the informative-central cue condition for the $300 \mathrm{~ms}$ SOA.

\section{Post-print (final draft post-refereeing)}




\section{INFORMATIVE-CENTRAL CUEING (SOA $700 \mathrm{~ms}$ )}

IPSILATERAL

PL

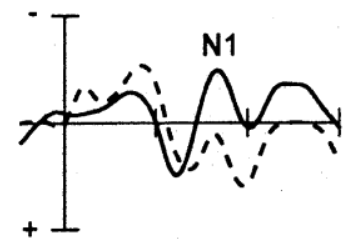

T5

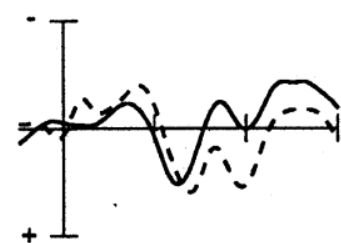

OL

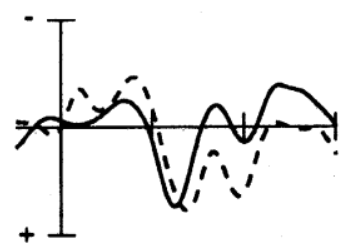

PR

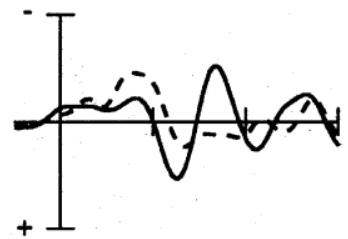

T6

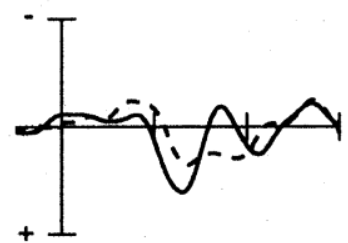

OR

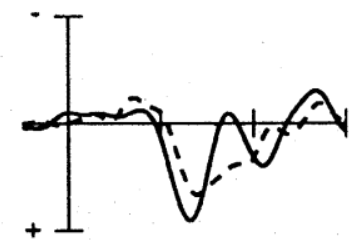

PL

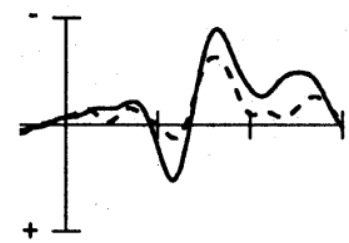

T5

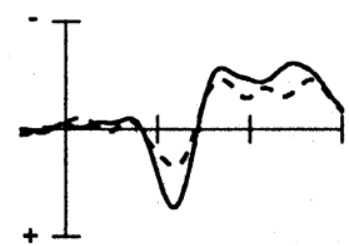

OL

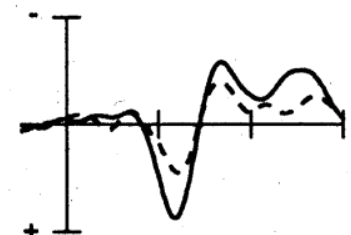

PR

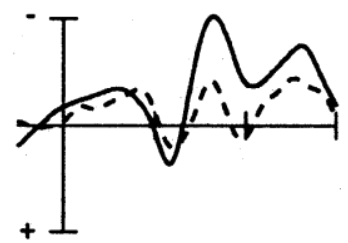

T6

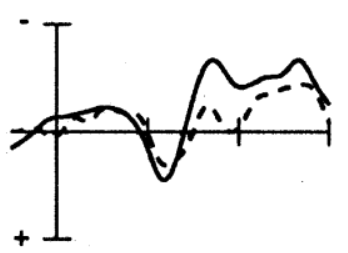

OR

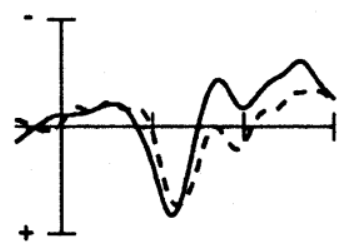

valid

invalid

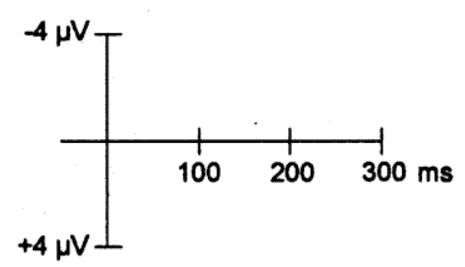

Figure 5. Grand-averaged ERPs for valid and invalid trials at parietal, temporal and occipital electrodes ipsilateral and contralateral to the target location in the informative-central cue condition for the $700 \mathrm{~ms}$ SOA.

\section{Post-print (final draft post-refereeing)}


INFORMATIVE-PERIPHERAL CUEING (SOA $300 \mathrm{~ms}$ )

IPSILATERAL

CONTRALATERAL

PL

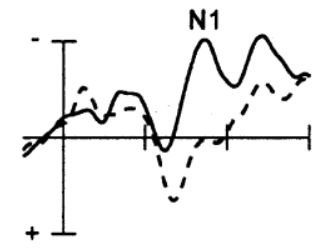

T5

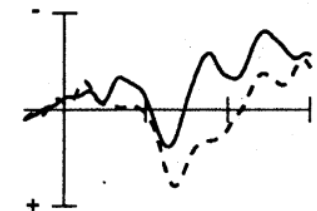

OL

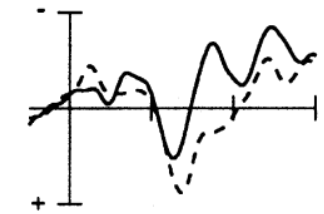

PR

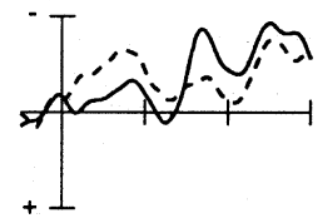

T6

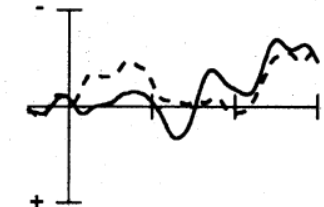

OR

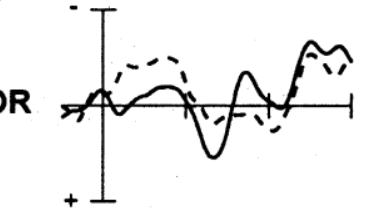

PL

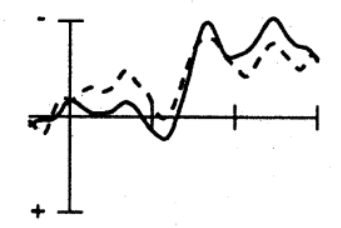

T5

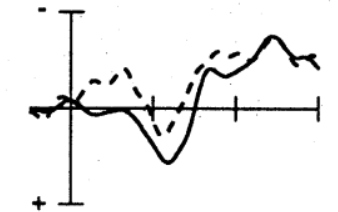

OL

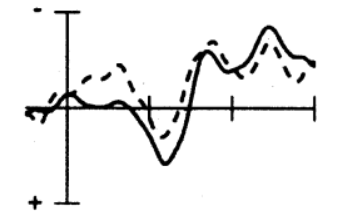

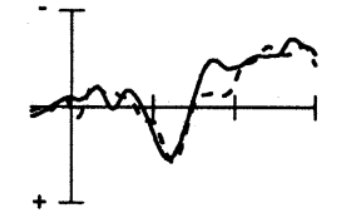
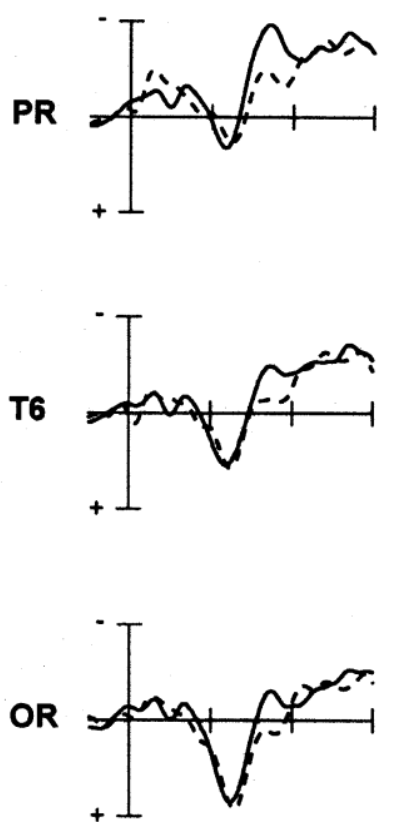
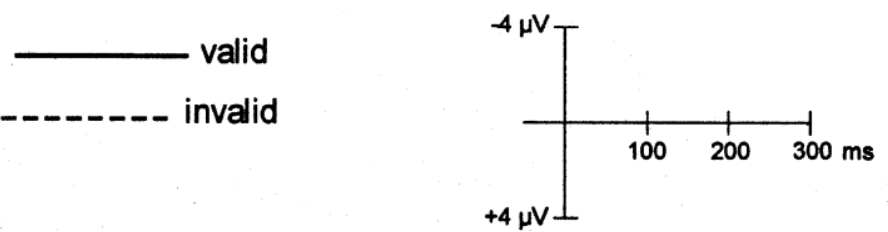

Figure 6. Grand-averaged ERPs for valid and invalid trials at parietal, temporal and occipital electrodes ipsilateral and contralateral to the target location in the informative-peripheral cue condition for the $300 \mathrm{~ms}$ SOA.

\section{Post-print (final draft post-refereeing)}


UNINFORMATIVE-PERIPHERAL CUEING (SOA $300 \mathrm{ms)}$

IPSILATERAL

CONTRALATERAL

PL
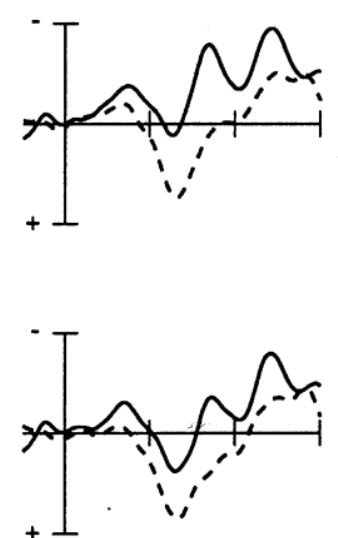

OL

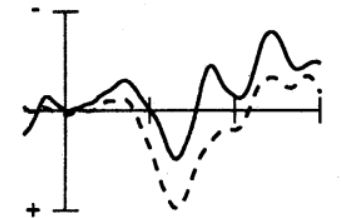

PR

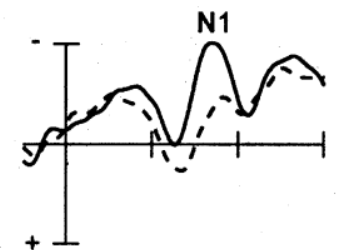

T6

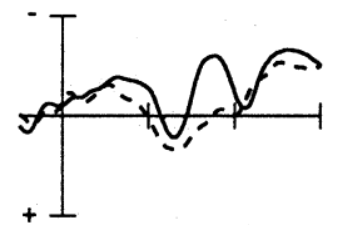

OR

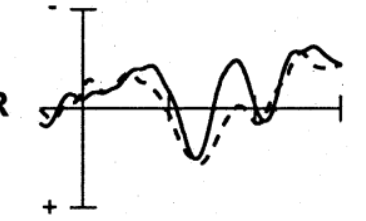

PL

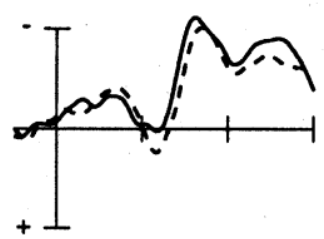

T5

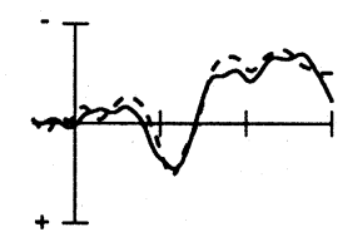

OL

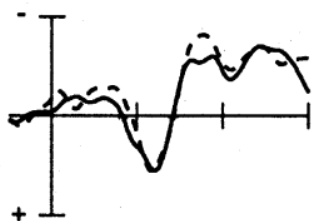

PR
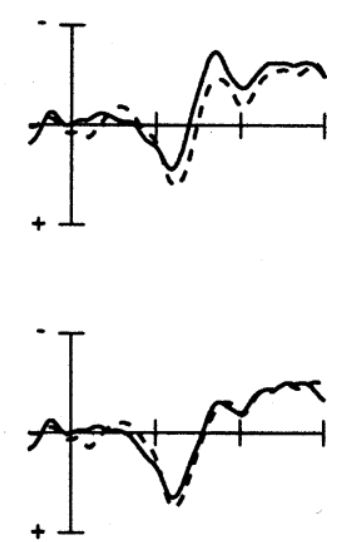

OR

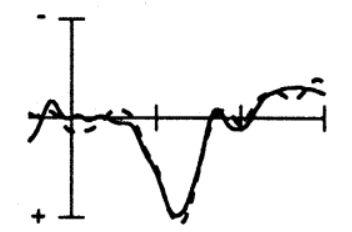

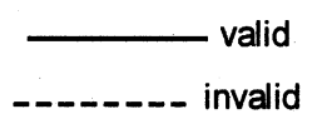

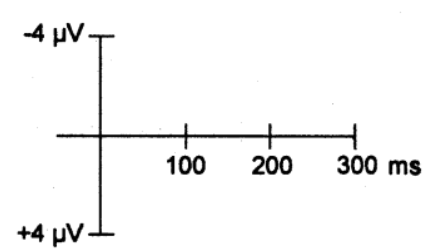

Figure 7. Grand-averaged ERPs for valid and invalid trials at parietal, temporal and occipital electrodes ipsilateral and contralateral to the target location in the uninformative-peripheral cue condition for the $300 \mathrm{~ms}$ SOA.

\section{Post-print (final draft post-refereeing)}

